Tropical Journal of Pharmaceutical Research February 2017; 16 (2): 379-386

ISSN: $1596-5996$ (print); 1596-9827 (electronic) (c) Pharmacotherapy Group, Faculty of Pharmacy, University of Benin, Benin City, 300001 Nigeria.

All rights reserved.

\title{
Spectrum-effect relationships between high performance liquid chromatography fingerprint and analgesic property of Anisodus tanguticus (Maxim) Pascher (Solanaceae) roots
}

\author{
Yun-Bin Jiang ${ }^{1}$, Mei Zhong ${ }^{2}$, Ming-Xun Hu${ }^{1}$, Ling Chen ${ }^{1}$, Yan Gou ${ }^{3}$, Juan Zhou ${ }^{3}$, \\ $\mathrm{Pi}-\mathrm{E} \mathrm{Wu}{ }^{3}$ and $\mathrm{Yu}$-Ying $\mathrm{Ma}^{{ }^{1 *}}$ \\ ${ }^{1}$ College of Pharmacy, Chengdu University of Traditional Chinese Medicine, Chengdu 611137, ${ }^{2}$ Analytical Chemistry \\ Department, West China Frontier Pharmatech Co., Ltd/National Chengdu Center for Safety Evaluation of Drugs, Chengdu \\ 610041, ${ }^{3}$ Laboratory for Traditional Chinese Medicine and Ethnic Medicine, Sichuan Institute for Food and Drug Control, \\ Chengdu 610079, PR China
}

*For correspondence: Email: cdtcmma@163.com

Received: 10 September 2016

Revised accepted: 11 January 2017

\begin{abstract}
Purpose: To investigate the spectrum-effect relationships between high performance liquid chromatography with photodiode array detection (HPLC-DAD) fingerprint and analgesic activity of Anisodus tanguticus (Maxim.) Pascher (Solanaceae) (AT) roots.

Methods: Analgesic activity of AT roots was evaluated by acetic acid-induced writhing test in mice. Fingerprint of AT roots was established by HPLC-DAD. After oral administration of AT roots extract, intra-gastric contents of caffeoylputrescine, anisodine, fabiatrin, scopolin, scopolamine, anisodamine and atropine in mice were determined by HPLC-DAD. Spectrum-effect relationships between HPLC$D A D$ fingerprint and analgesic activity were investigated using bivariate correlation analysis.

Results: Following treatment with different batches of AT roots extract, acetic acid-induced writhing responses in mice were inhibited significantly ( $p<0.05$ or 0.01 ), with inhibitions of $26.62-55.13 \%$, relative to the control group. Sixteen common peaks were obtained by fingerprint analysis. Peaks 1,2 , 6, 7, 8, 9 and 12 were identified as caffeoylputrescine, anisodine, fabiatrin, scopolin, scopolamine, anisodamine and atropine, respectively. Bivariate correlation analysis between analgesic activity of AT roots and 16 common peaks areas indicated the contributions of 16 common peaks to analgesic activity of AT roots. Surprisingly, bivariate correlation analysis between analgesic activity of AT roots and intragastric contents of above-named 7 constituents revealed that the contributions of the 7 constituents to analgesic activity of AT roots were different from those based on their peak areas.

Conclusion: This study provides scientific justification for the investigation of the active constituents of AT root with a view to its standardization.
\end{abstract}

Keywords: Anisodus tanguticus root, Analgesic activity, HPLC-DAD fingerprint, Bivariate correlation analysis

Tropical Journal of Pharmaceutical Research is indexed by Science Citation Index (SciSearch), Scopus, International Pharmaceutical Abstract, Chemical Abstracts, Embase, Index Copernicus, EBSCO, African Index Medicus, JournalSeek, Journal Citation Reports/Science Edition, Directory of Open Access Journals (DOAJ), African Journal Online, Bioline International, Open-J-Gate and Pharmacy Abstracts

\section{INTRODUCTION}

The main chemical constituents of Anisodus tanguticus (Maxim.) Pascher (Solanaceae) (AT) roots are alkaloids, flavonoids, coumarins and phenolcarboxylic acid [1]. Existing reports about AT roots are primarily focused on contents of the main alkaloids anisodamine, anisodine, 
scopolamine and atropine [2-4]. It is recorded in Chinese Tibetan medicine and China flora that AT roots exhibit sedative, analgesic and antitussive activities, but there have been no studies to confirm these pharmacologic effects $[1,5]$.

AT roots have been used as raw material in the extraction of tropane alkaloids for a long time [5]. With increasing demand for tropane alkaloids, the demand for AT roots is growing rapidly [6]. To avoid wastage of AT roots during extraction of tropane alkaloids, a feasible solution is to promote their application as medicinal herbs for treating diseases. The scientific quality standard of AT roots is a pre-condition for their use in treating diseases. Quality standards of medicinal herbs in Chinese Pharmacopoeia show that quantitative determinations of active constituents are very important in assessing the quality of medicinal herbs [7].

This study aimed at investigating the active constituents of AT roots through spectrum-effect relationships, an acceptable method used to exploring the active constituents of medicinal herbs [8,9]. Spectrum-effect relationships between high performance liquid chromatography with photodiode array detection (HPLC-DAD) fingerprint and analgesic activity of AT roots were investigated using bivariate correlation analysis.

\section{EXPERIMENTAL}

\section{Plant material}

Eighteen batches of AT roots (Table 1) were collected from different districts of Sichuan
Province in China and identified by Prof Yu-Ying $\mathrm{Ma}$, a taxonomist in the College of Pharmacy, Chengdu University of Traditional Chinese Medicine. The voucher specimens of AT roots (voucher no. Sldjiang/CDUTCM S1 - S18) were deposited at the Herbarium of Chengdu University of Traditional Chinese Medicine for future reference.

\section{Instrumentation, chemicals and reagents}

HPLC analysis was carried out on LC-20AT (SHIMADZU, Japan). HPLC grade acetonitrile and methanol were purchased from Fisher (Fisher Scientific, Germany). Analytical grade $\mathrm{KH}_{2} \mathrm{PO}_{4}, \mathrm{H}_{3} \mathrm{PO}_{4}$, hydrochloric acid, ethanol, acetic acid and sodium carboxyl methyl cellulose (CMC-Na) were purchased from Chengdu Kelon Chemical Reagent Factory (Chengdu, China). Ultra-pure water was prepared by Milli-Q Advantage A10 (Millipore, USA). Enteric-coated aspirin tablets were purchased from Yabao Pharmaceutical Group Co., Ltd. (Taiyuan, China). Anisodine hydrobromide, scopolamine hydrobromide, anisodamine hydrobromide and atropine sulfate were purchased from National Institutes for Food and Drug Control (Beijing, China), and their purities were 100, 91.7, 99.4 and $96.5 \%$, respectively. Caffeoylputrescine, fabiatrin and scopolin were separated from AT roots, and their purities were 97.6, 97.6 and 94.6 $\%$, respectively.

\section{Animals}

Specific pathogen-free male and female KM mice (mean weight $=20 \pm 2 \mathrm{~g}$ ) were purchased from Chengdu Dashuo Laboratory Animal Co. LTD (Chengdu, China).

Table 1: Basic information on AT roots

\begin{tabular}{lcccc}
\hline No. & Source & $\begin{array}{c}\text { Latitude and longitude } \\
(\mathbf{N}, \mathbf{E})\end{array}$ & $\begin{array}{c}\text { Altitude } \\
(\mathbf{m})\end{array}$ & Collection time \\
\hline S1 & Dege, Sichuan & $31^{\circ} 48^{\prime} 48.76^{\prime \prime}, 99^{\circ} 25^{\prime} 12.84^{\prime \prime}$ & 3715 & August 2013 \\
S2 & Dege, Sichuan & $31^{\circ} 58^{\prime} 24.29^{\prime \prime}, 98^{\circ} 40^{\prime} 59.36^{\prime \prime}$ & 3600 & July 2013 \\
S3 & Dege, Sichuan & $31^{\circ} 55^{\prime} 39.78^{\prime \prime}, 99^{\circ} 12^{\prime} 07.85^{\prime \prime}$ & 3867 & July 2013 \\
S4 & Shiqu, Sichuan & $33^{\circ} 01^{\prime} 17.07^{\prime \prime}, 98^{\circ} 09^{\prime} 18.10^{\prime \prime}$ & 4106 & June 2013 \\
S5 & Shiqu, Sichuan & $33^{\circ} 01^{\prime} 55.02^{\prime \prime}, 98^{\circ} 16^{\prime} 07.93^{\prime \prime}$ & 4151 & June 2013 \\
S6 & Baiyu, Sichuan & $3^{\circ} 07^{\prime} 27.37^{\prime \prime}, 99^{\circ} 21^{\prime} 53.85^{\prime \prime}$ & 3899 & June 2013 \\
S7 & Litang, Sichuan & $2^{\circ} 49^{\prime} 52.30^{\prime \prime}, 99^{\circ} 49^{\prime} 15.05^{\prime \prime}$ & 3947 & July 2013 \\
S8 & Litang, Sichuan & $2^{\circ} 44^{\prime} 49.30^{\prime \prime}, 99^{\circ} 48^{\prime} 02.41^{\prime \prime}$ & 3623 & July 2013 \\
S9 & Litang, Sichuan & $29^{\circ} 59^{\prime} 17.19^{\prime \prime}, 100^{\circ} 13^{\prime} 16.74^{\prime \prime}$ & 3959 & July 2013 \\
S10 & Litang, Sichuan & $30^{\circ} 13^{\prime} 19.10^{\prime \prime}, 99^{\circ} 49^{\prime} 21.77^{\prime \prime}$ & 4181 & July 2013 \\
S11 & Luhuo, Sichuan & $31^{\circ} 23^{\prime} 37.27^{\prime \prime}, 100^{\circ} 40^{\prime} 49.06^{\prime \prime}$ & 3220 & July 2013 \\
S12 & Luhuo, Sichuan & $31^{\circ} 3^{\prime} 58.40^{\prime \prime}, 100^{\circ} 45^{\prime} 16.33^{\prime \prime}$ & 3620 & July 2013 \\
S13 & Seda, Sichuan & $31^{\circ} 59^{\prime} 29.78^{\prime \prime}, 100^{\circ} 40^{\prime} 49.54^{\prime \prime}$ & 3473 & July 2013 \\
S14 & Seda, Sichuan & $32^{\circ} 0^{\prime} 129.42^{\prime \prime}, 100^{\circ} 30^{\prime} 51.42^{\prime \prime}$ & 3655 & July 2013 \\
S15 & Kangding, Sichuan & $30^{\circ} 19^{\prime} 09.12^{\prime \prime}, 101^{\circ} 31^{\prime} 22.83^{\prime \prime}$ & 3736 & July 2013 \\
S16 & Aba, Sichuan & $32^{\circ} 49^{\prime} 23.34^{\prime \prime}, 101^{\circ} 50^{\prime} 57.51^{\prime \prime}$ & 3259 & August 2013 \\
S17 & Ruoergai, Sichuan & $33^{\circ} 24^{\prime} 38.00^{\prime \prime}, 102^{\circ} 28^{\prime} 03.44^{\prime \prime}$ & 3440 & August 2013 \\
S18 & Hongyuan, Sichuan & $32^{\circ} 54^{\prime} 57.98^{\prime \prime}, 102^{\circ} 38^{\prime} 12.14^{\prime \prime}$ & 3487 & August 2013 \\
\hline
\end{tabular}


All mice were housed in a temperature-controlled vivarium $\left(25^{\circ} \mathrm{C}\right)$ with relative humidity of $65 \%$ and 12/12-h light-dark cycle. They were given water and feed ad libitum. All animal treatments were conducted in strict compliance with the National Institutes of Health Guide for Care and Use of Laboratory Animals [10]. All animal experiments in this study were performed with the approval of the Ethics Committee of Chengdu University of Traditional Chinese Medicine (protocol no. CDUTCM 20150412).

\section{Sample preparation for acetic acid-induced writhing test}

AT roots (10 g/batch) were ground into powder and extracted 6 times by cold maceration in 50 $\mathrm{mL}$ of ethanol (95\%) containing $0.1 \%$ hydrochloric acid with intermittent shaking at $3 \mathrm{~h}$ intervals for $24 \mathrm{~h}$. The extracts were combined and concentrated under reduced pressure to yield a crude extract $(10 \mathrm{~mL})$. The extract was diluted 10 times with $0.5 \% \mathrm{CMC}-\mathrm{Na}$ to obtain the pharmacodynamic sample.

\section{Animal grouping and treatment}

The mice were randomly divided into 20 groups $(n=10)$ : control, aspirin and S1 - S18 groups. Mice in the aspirin group were administrated aspirin at a dose of $0.1 \mathrm{~g} / \mathrm{kg}$ once a day for 5 days. Prior to administration, aspirin was ground into powder and then dissolved in $0.5 \% \mathrm{CMC}-\mathrm{Na}$ to obtain a concentration of $0.005 \mathrm{~g} / \mathrm{mL}$. Mice in the S1 - S18 groups were administrated the corresponding AT roots extract at a dose of 2 $\mathrm{mL} / \mathrm{kg}$ (crude extract/mice body weight) once a day for 5 days, respectively. Mice in the control group received $0.5 \%$ CMC-Na once a day for 5 days. All treatments were given by gavage (20 $\mathrm{mL} / \mathrm{kg}$ ). After $30 \mathrm{~min}$ of drug treatment on the 5th day, mice in all groups were injected intraperitoneally with $0.7 \%$ acetic acid at a dose of $10 \mathrm{~mL} / \mathrm{kg}$. Fifteen minutes after the acetic acid injection, the number of writhes of each mouse were determined. The \% inhibition $(\mathrm{H})$ of writhing response by aspirin or AT roots extract were calculated as in Eq 1.

$H(\%)=\{(A-B) / A\} 100$

where $A$ and $B$ stand for the number of writhes in the control group and the aspirin or S1 - S18 groups, respectively.

\section{Sample preparation for HPLC analysis}

Sample preparation for HPLC analysis was the same as that for acetic acid-induced writhing test, except for the last dilution. In this case, the
AT roots extract sample for HPLC analysis was diluted 20 times with methanol. The diluted extract was filtered through $0.2 \mu \mathrm{m}$ membrane before HPLC analysis.

\section{Preparation of mixed standard solutions}

Appropriate quantities of anisodine, scopolamine, anisodamine and atropine were dissolved in methanol to produce $3.497,0.229,0.827$ and $0.353 \mathrm{mg} / \mathrm{mL}$ of stock solutions, respectively. Appropriate quantities of caffeoylputrescine, fabiatrin and scopolin were dissolved in $60 \%$ methanol to produce 1.188, 1.761 and 1.058 $\mathrm{mg} / \mathrm{mL}$ of stock solutions, respectively. Appropriate volume of stock solution of the 7 constituent standards were added into same volumetric flask and diluted with methanol to obtain a series of mixed working standard solution of different concentrations.

\section{HPLC conditions}

HPLC analysis was performed on Shimadzu LC20AT, equipped with a binary solvent delivery pump, an auto sampler and a DAD detector; and connected to Empower 2 software. The chromatographic separation was carried out on an Inertsil ODS-SP $\mathrm{C}_{18}(4.6 \mathrm{~mm} \times 250 \mathrm{~mm}, 5$ $\mu \mathrm{m})$, operated at $30{ }^{\circ} \mathrm{C}$. The mobile phase was composed of acetonitrile (A) and $10 \mathrm{mmol} / \mathrm{L}$ $\mathrm{KH}_{2} \mathrm{PO}_{4}$ buffer solution (B; the $\mathrm{pH}$ was adjusted to 3.0 with $\mathrm{H}_{3} \mathrm{PO}_{4}$ ), with a linear gradient of $\mathrm{A}$ : 0 $5 \min (10 \%), 5$ - $40 \min (10-25 \%), 40-41 \min$ (25 - $90 \%), 41-50 \min (90 \%), 50-55 \min (90$ - $10 \%)$ and $55-60 \mathrm{~min}(10 \%)$. The injection volume and the flow rate were $10 \mu \mathrm{L}$ and 1.0 $\mathrm{mL} / \mathrm{min}$, respectively. Detection wavelength of HPLC fingerprint and determination of contents of anisodine, scopolamine, anisodamine and atropine was $210 \mathrm{~nm}$, while detection wavelength for caffeoylputrescine was $317 \mathrm{~nm}$. Detection wavelength for contents of fabiatrin and scopolin was $339 \mathrm{~nm}$. HPLC chromatogram of $0-40$ min was recorded and used to analyze HPLC fingerprint and determine the levels of the abovenamed 7 constituents.

\section{Validation of HPLC method}

Precision, stability within $24 \mathrm{~h}$ and repeatability were used to validate the HPLC fingerprint method. Precision, stability within $24 \mathrm{~h}$, repeatability, limit of detection (LOD), limit of quantitation (LOQ) and linearity range were used to validate the content determination method for the above-named 7 constituents. Precision, stability and repeatability were used to assess instrument performance, stability of target constituent and operation consistency, 
respectively [11]. LOD and LOQ were deemed to be the content that came into being a signal to noise $(\mathrm{S} / \mathrm{N})$ of 3 and 10 , respectively. Linearity range was used to assess the linear relationship between injection content of target constituent and its peak area.

\section{Statistical analysis}

Data from acetic acid-induced writhing test are presented as mean \pm standard deviation (SD). Differences among different groups were analyzed by one-way ANOVA on SPSS 21.0, and were considered to be statistically significant at $p<0.05$ or 0.01 . Common peaks and similarities among different batches of AT roots were evaluated by Similarity Evaluation System for Chromatographic Fingerprint of TCM (SESCF, Version 2004A). Bivariate correlation analysis between \% inhibition of AT roots extract against writhing responses and common peak areas, or intra-gastric contents of the 7 constituents (caffeoylputrescine, anisodine, fabiatrin, scopolin, scopolamine, anisodamine and atropine) in mice was performed with Pearson's correlation coefficient on SPSS 21.0.

\section{RESULTS}

\section{Inhibitory effect of AT roots extract on acetic acid-induced writhing responses}

Compared with the control group, the acetic acidinduced writhing responses in the aspirin group were significantly inhibited $(p<0.01)$, with inhibition of $65.40 \%$, indicating that the acetic acid-induced writhing model and positive drug aspirin were successfully established and administrated, respectively. After treatment with AT roots extract (S1 - S18), the acetic acidinduced writhing responses were significantly reduced $(p<0.05$ or 0.01$)$, with inhibitions of 26.62 - $55.13 \%$, compared with the control group. These results are shown in Table 2.

\section{Validation of HPLC fingerprint method}

The results of precision, stability within $24 \mathrm{~h}$ and repeatability indicated that the relative standard deviation (RSD, $n=6$ ) of retention time and peak area values of 16 common peaks were less than $2 \%$, suggesting that the method was suitable and feasible for analyzing HPLC fingerprint of AT roots extract [12].

Table 2: Inhibitory effect of AT roots extract on acetic acid-induced writhing responses

\begin{tabular}{|c|c|c|}
\hline Group & No. of writhes (mean \pm SD) & $\%$ Inhibition \\
\hline Control & $26.30 \pm 3.23$ & - \\
\hline Aspirin & $9.10 \pm 2.33^{\pi \pi}$ & 65.40 \\
\hline S1 & $18.40 \pm 4.33^{\pi \pi}$ & 30.04 \\
\hline S2 & $18.50 \pm 6.02^{n}$ & 29.66 \\
\hline S3 & $17.60 \pm 6.26 n$ & 33.08 \\
\hline S4 & $18.10 \pm 6.44^{\pi \pi}$ & 31.18 \\
\hline S5 & $19.30 \pm 4.24^{\pi}$ & 26.62 \\
\hline S6 & $19.20 \pm 7.02^{\star}$ & 27.00 \\
\hline S7 & $14.30 \pm 4.32^{n}$ & 45.63 \\
\hline S8 & $18.30 \pm 4.24$ & 30.42 \\
\hline S9 & $13.80 \pm 6.11^{n}$ & 47.53 \\
\hline S10 & $17.70 \pm 5.38^{\approx \pi}$ & 32.70 \\
\hline S11 & $16.20 \pm 4.96^{\star \pi}$ & 38.40 \\
\hline $\mathrm{S} 12$ & $11.80 \pm 3.19^{n}$ & 55.13 \\
\hline $\mathrm{S} 13$ & $17.10 \pm 4.43$ & 34.98 \\
\hline S14 & $13.80 \pm 4.29$ & 47.53 \\
\hline S15 & $13.00 \pm 3.59^{\pi \pi}$ & 50.57 \\
\hline S16 & $18.60 \pm 3.75^{\star x}$ & 29.28 \\
\hline S17 & $15.70 \pm 5.96^{\star \pi}$ & 40.30 \\
\hline S18 & $13.40 \pm 4.53^{\prime}$ & 49.05 \\
\hline
\end{tabular}

\section{Content method validation of test constituents}

The results of precision, stability within $24 \mathrm{~h}$ and repeatability revealed that the RSD of the peak areas $(n=6)$ were less than $2 \%$. The LOD, LOQ, calibration equation, coefficient of determination $\left(R^{2}\right)$ and linearity range are presented in Table 3 . The calibration equation was generated according to the linear relationship between peak area values $(Y$ ) and injection content $(X \mu \mathrm{g})$ of standard. These results showed that the method was suitable and feasible for determination of the contents of the test constituents (caffeoylputrescine, anisodine, fabiatrin, scopolin, scopolamine, anisodamine and atropine).

Table 3: Validation data for test constituents

\begin{tabular}{lccccc}
\hline Constituent & $\begin{array}{c}\text { LOD } \\
(\boldsymbol{\mu g})\end{array}$ & $\begin{array}{c}\text { LOQ } \\
(\boldsymbol{\mu g})\end{array}$ & Calibration equation & $\boldsymbol{R}^{2}$ & $\begin{array}{c}\text { Linearity range } \\
(\boldsymbol{\mu g})\end{array}$ \\
\hline Caffeoylputrescine & 0.002 & 0.008 & $y=2683458.2378 x-87306.2691$ & 0.9991 & $0.010-5.938$ \\
Anisodine & 0.023 & 0.076 & $y=854503.5283 x+32827.0065$ & 0.9996 & $0.175-3.497$ \\
Fabiatrin & 0.006 & 0.019 & $y=1328578.8071 x-20089.5685$ & 0.9999 & $0.035-8.804$ \\
Scopolin & 0.004 & 0.013 & $y=1824191.2968 x+29315.4691$ & 0.9996 & $0.021-5.292$ \\
Scopolamine & 0.029 & 0.097 & $y=959196.7164 x-13215.9341$ & 0.9999 & $0.114-4.578$ \\
Anisodamine & 0.043 & 0.145 & $y=788614.0684 x+24978.4081$ & 0.9999 & $0.165-4.133$ \\
Atropine & 0.110 & 0.368 & $y=919355.7881 x+28438.1254$ & 0.9999 & $0.530-7.063$ \\
\hline
\end{tabular}




\section{HPLC fingerprint analysis}

The HPLC chromatograms of 18 batches of AT roots extract were imported into SESCF to generate reference standard fingerprint including 16 characteristic peaks (common peaks) by multipoint correction and peak matching (Figure 1). Similarities among HPLC chromatograms of 18 batches of AT roots extract and reference standard fingerprint were analyzed. The RSD of the 16 common peaks areas in 18 batches of AT roots samples were all higher than $40 \%$, indicating that the areas of each common peak in different samples varied widely. The similarities among HPLC chromatograms of 18 batches of AT roots extract were in range $0.661-0.985$. Similarities between HPLC chromatograms of 18 batches of AT roots extract and reference standard fingerprint were in range $0.811-0.988$.

\section{Identification of common peaks}

The common peaks $1,2,6,7,8,9$ and 12 were identified as caffeoylputrescine, anisodine, fabiatrin, scopolin, scopolamine, anisodamine and atropine, respectively, by comparing retention time and ultraviolet absorption curves of target peaks with those of standards (Figure 2).

\section{Intra-gastric contents of test compounds in mice}

The content of each constituent in HPLC sample was calculated from its peak area and standard curve (Table 3). The intra-gastric content of each target constituent in mice $(\mathrm{mg} / \mathrm{kg} /$ day) was then calculated according to its content in HPLC sample, difference between HPLC and pharmacodynamic sample, and intra-gastric volume. These results are shown in Table 4.

\section{Bivariate correlation analysis}

Bivariate correlation analysis between \% inhibition of AT roots extract against writhing responses and 16 common peaks areas, or intragastric contents of test constituents in mice were performed with Pearson's correlation coefficient on SPSS 21.0. The results of bivariate correlation analysis between \% inhibition of AT roots extract and 16 common peaks areas (Table 5: correlation coefficient A) showed that the contributions of 16 common peaks to analgesic activity of AT roots extract were in the following order: peak 12 (atropine) $>8$ (scopolamine) $>13$ $>7$ (scopolin) $>9$ (anisodamine) $>11>10>4>$ 2 (anisodine) $>5>15>6$ (fabiatrin) $>1$ (caffeoylputrescine) $>16>14>3$.

The results of bivariate correlation analysis between \% inhibition of AT roots extract and intra-gastric contents of test constituents in mice (Table 5: correlation coefficient B) indicated that the contributions of test constituents to analgesic activities of AT roots extract were in the following order: atropine $>$ anisodamine $>$ scopolamine $>$ scopolin > anisodine > fabiatrin > caffeoylputrescine.

\section{DISCUSSION}

Reports so far show that the main constituents of AT roots are alkaloids [13-15]. Thus it is desirable to increase the efficiency of extraction of alkaloids from AT roots sample preparation. Alkaloids in medicinal herbs are extracted with water or ethanol containing inorganic acid $[16,17]$. In the present study, ethanol was selected as the extraction solvent because it has

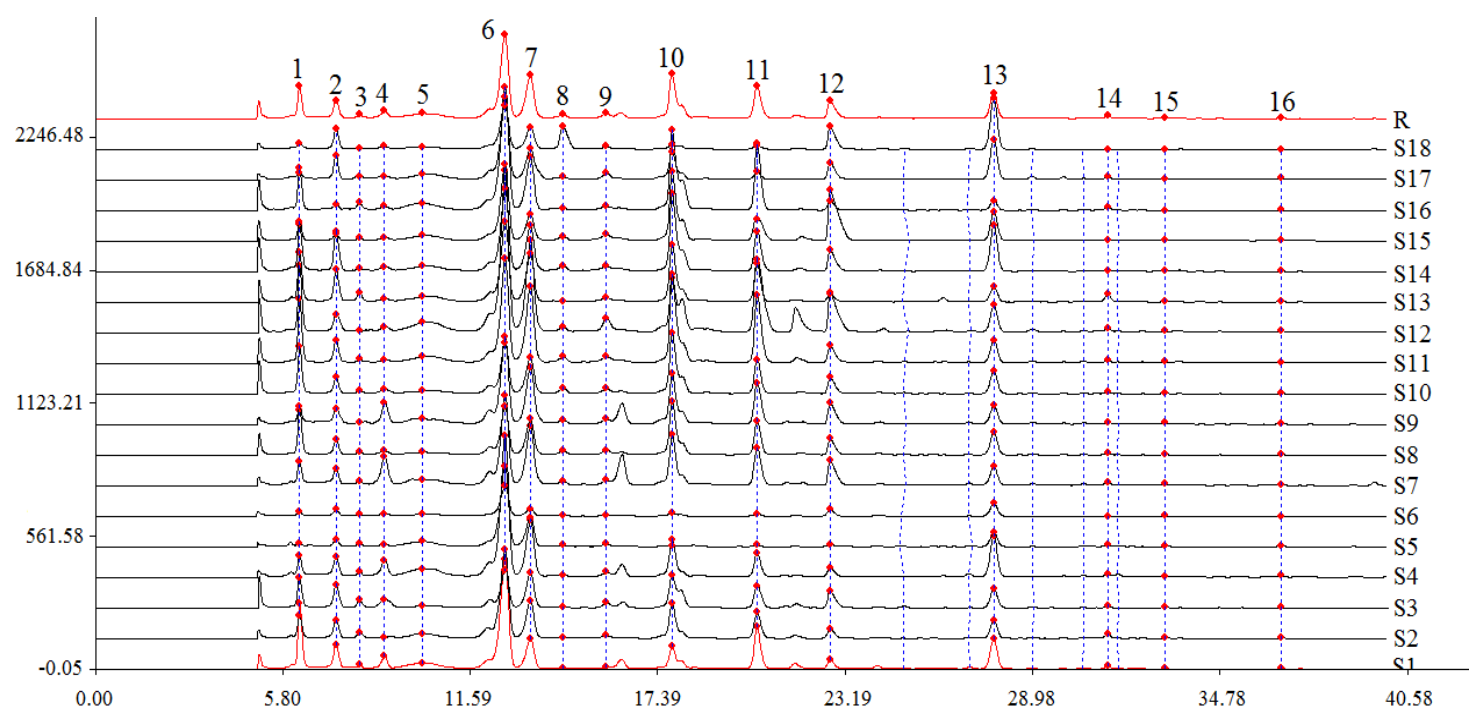

Figure 1: HPLC chromatograms of 18 batches of AT roots extract (S1 - S18) and reference standard fingerprint (R) including 16 common peaks (peaks 1 - 16) 

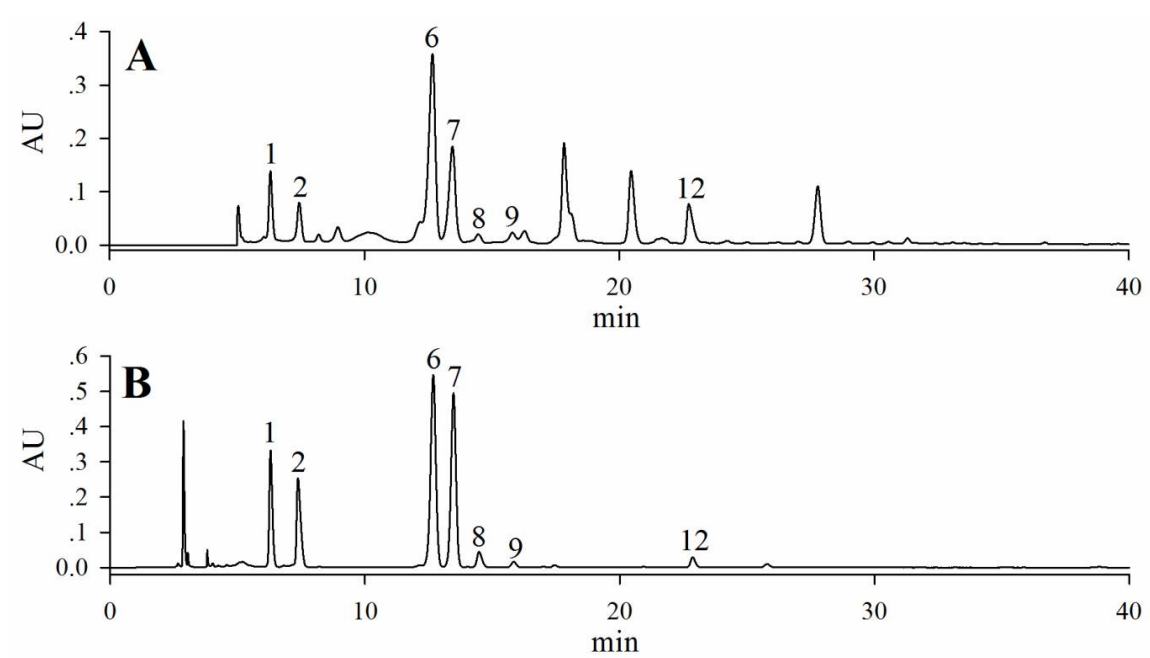

Figure 2: HPLC chromatograms of reference standard fingerprint $(A)$ and mixed standards (B); Peak 1: caffeoylputrescine; 2: anisodine; 6: fabiatrin; 7: scopolin; 8: scopolamine; 9: anisodamine; 12: atropine

Table 4: Intra-gastric contents of test constituents in mice (mg/kg/day)

\begin{tabular}{lccccccc}
\hline Group & Caffeoylputrescine & Anisodine & Fabiatrin & Scopolin & Scopolamine & Anisodamine & Atropine \\
\hline S1 & 5.17 & 5.39 & 10.87 & 2.28 & 0.09 & 0.15 & 2.16 \\
S2 & 1.79 & 4.08 & 8.57 & 2.86 & 0.14 & 0.57 & 2.30 \\
S3 & 2.51 & 5.19 & 3.95 & 2.67 & 0.21 & 1.28 & 4.90 \\
S4 & 1.38 & 4.25 & 13.65 & 4.35 & 0.24 & 0.79 & 2.35 \\
S5 & 0.31 & 1.38 & 9.00 & 2.17 & 0.35 & 0.70 & 0.51 \\
S6 & 0.37 & 1.35 & 3.26 & 0.46 & 0.40 & 0.28 & 1.78 \\
S7 & 1.73 & 3.15 & 8.46 & 4.50 & 0.97 & 0.55 & 7.20 \\
S8 & 3.53 & 3.08 & 4.58 & 2.73 & 1.18 & 0.96 & 4.21 \\
S9 & 1.30 & 3.00 & 8.08 & 4.33 & 1.02 & 0.65 & 5.97 \\
S10 & 3.63 & 3.32 & 4.79 & 2.82 & 1.55 & 1.03 & 4.42 \\
S11 & 4.84 & 4.67 & 10.06 & 5.87 & 1.54 & 1.17 & 4.52 \\
S12 & 5.00 & 3.62 & 15.19 & 7.21 & 0.89 & 3.86 & 13.72 \\
S13 & 3.68 & 6.92 & 7.97 & 3.74 & 0.10 & 0.90 & 2.06 \\
S14 & 3.42 & 8.60 & 8.35 & 3.47 & 1.46 & 0.92 & 5.92 \\
S15 & 1.50 & 1.08 & 7.47 & 2.01 & 1.33 & 1.48 & 19.44 \\
S16 & 3.28 & 0.66 & 12.01 & 4.21 & 0.13 & 0.64 & 2.11 \\
S17 & 0.42 & 5.01 & 8.02 & 2.24 & 0.67 & 1.62 & 4.70 \\
S18 & 0.45 & 3.99 & 4.59 & 1.58 & 6.44 & 0.65 & 6.40 \\
\hline
\end{tabular}

higher extracting capacity than water. The temperature used for concentrating a water extract is higher than that for an ethanol extract. This may result in the decomposition of some constituents of water extract of AT roots. Based on these reasons, acidified ethanol was selected as the extraction solvent for AT roots.

Methanol and acetonitrile are two commonly used organic mobile phases in HPLC. Acetonitrile was selected as the organic mobile phase in this work to obtain steady base line of HPLC chromatogram at $210 \mathrm{~nm}$. Since there are many alkaloids in AT roots, $\mathrm{KH}_{2} \mathrm{PO}_{4}$ buffer solution was selected as the aqueous mobile phase to obtain good peak shapes and separation of alkaloids, and the $\mathrm{pH}$ value of $\mathrm{KH}_{2} \mathrm{PO}_{4}$ buffer solution was adjusted to 3.0 with $\mathrm{H}_{3} \mathrm{PO}_{4}$ based on preliminary experiments. The
HPLC chromatogram at $210 \mathrm{~nm}$ provided more information on constituents, and the maximum absorption wavelength of main alkaloids (anisodine, scopolamine, anisodamine and atropine) was also $210 \mathrm{~nm}$. Thus the HPLC chromatogram at $210 \mathrm{~nm}$ was used to establish HPLC fingerprint. The detection wavelengths for the determination of contents of caffeoylputrescine, anisodine, fabiatrin, scopolin, scopolamine, anisodamine and atropine were selected based on their 190 - $800 \mathrm{~nm}$ absorption curves.

Acetic acid-induced writhing test is a common model for investigating the analgesic activities of drugs [18]. Aspirin is an accepted drug used to inhibit acetic acid-induced writhing response [19]. Therefore, acetic acid-induced writhing test was used to evaluate analgesic activity of AT roots, with aspirin as positive drug. 
Table 5: Correlation coefficient data between \% inhibition of AT roots extract against writhing responses and 16 common peaks areas (correlation coefficient $A$ ), or intra-gastric contents of test constituents in mice (correlation coefficient B)

\begin{tabular}{lc|lc}
\hline Peak no. & Correlation coefficient A & Constituent & Correlation coefficient B \\
\hline 1 & 0.137 & Caffeoylputrescine & 0.044 \\
2 & 0.267 & Anisodine & 0.178 \\
3 & -0.389 & - & - \\
4 & 0.272 & - & - \\
5 & 0.241 & - & - \\
6 & 0.204 & Fabiatrin & 0.176 \\
7 & 0.444 & Scopolin & 0.399 \\
8 & 0.591 & Scopolamine & 0.484 \\
9 & 0.433 & Anisodamine & 0.558 \\
10 & 0.294 & - & - \\
11 & 0.378 & - & - \\
12 & 0.796 & Atropine & 0.794 \\
13 & 0.475 & - & - \\
14 & -0.186 & - & - \\
15 & 0.220 & - & - \\
16 & -0.142 & - & - \\
\hline
\end{tabular}

The similarity values $(0.811-0.988)$ between HPLC chromatograms of 18 batches of AT roots extract and reference standard fingerprint were higher than the similarity values $(0.661-0.985)$ among HPLC chromatograms of 18 batches of AT roots extract. This indicated that the 16 common peaks can well represent information on chemical constituents in AT roots extract.

The higher the correlation coefficient is, the higher the contribution of the corresponding peak to analgesic activity of AT roots extract is [20]. The results (Table 5: correlation coefficient $A$ ) revealed that the contributions of 16 common peaks to analgesic activity of AT roots extract were in the order: peak 12 (atropine) $>8$ (scopolamine) $>13>7$ (scopolin) $>9$ (anisodamine) $>11>10>4>2$ (anisodine) $>5$ $>15>6$ (fabiatrin) $>1$ (caffeoylputrescine) $>16$ $>14>3$. Since the ultraviolet absorptions of different constituents are different, the differences of peak areas among different constituents cannot represent differences in their contents. Therefore, the correlation analysis between \% inhibition of AT roots extract against writhing responses and intra-gastric contents of test constituents in mice were further carried out. The results (Table 5: correlation coefficient $\mathrm{B}$ ) indicated that the contributions of test constituents to analgesic activity of AT roots extract were in the order: atropine $>$ anisodamine $>$ scopolamine $>$ scopolin $>$ anisodine $>$ fabiatrin $>$ caffeoylputrescine; and the order and correlation coefficient were different from those based on their peaks areas. This suggests that the result of correlation analysis based on content of constituent may be more convincing than that based on corresponding peak area. This is a novel finding because correlation analyses for spectrum-effect relationships in all existing literature were performed by peak area [21-23].

\section{CONCLUSION}

The spectrum-effect relationships between analgesic activity and HPLC-DAD fingerprint of AT roots were investigated in this study for the first time. The correlation analysis between analgesic activity of AT roots and 16 common peaks areas indicate the contributions of 16 common peaks to analgesic activity of AT roots. Surprisingly, the correlation analysis between analgesic activity of AT roots extract and intragastric contents of test constituents show that the contributions of the test constituents to analgesic activity of AT roots are different from those based on their peak areas. This study provides scientific justification for the investigation of the active constituents of AT root with a view to its standardization.

\section{DECLARATIONS}

\section{Acknowledgement}

This work was supported by a grant from Science and Technology Support Plan Project of Sichuan Province in China (no. 2013SZ0115).

\section{Conflict of Interest}

No conflict of interest associated with this work.

\section{Contribution of Authors}

The authors declare that this work was done by the authors named in this article and all liabilities pertaining to claims relating to the content of this 
article will be borne by them. Yun-Bin Jiang and Mei Zhong contributed equally to this work.

\section{Open Access}

This is an Open Access article that uses a funding model which does not charge readers or their institutions for access and distributed under the terms of the Creative Commons Attribution License (http://creativecommons.org/licenses/by/ 4.0) and the Budapest Open Access Initiative (http://www.budapestopenaccessinitiative.org/rea d), which permit unrestricted use, distribution, and reproduction in any medium, provided the original work is properly credited.

\section{REFERENCES}

1. Drug Control Institute of Qinghai, Tibetan Medicine Research Institute of Qinghai. Chinese Tibetan medicine (Volume I). Shanghai Scientific and Technical Publishers: Shanghai; 1996; pp 195-202.

2. Li L, Wang J, Wang W, Lu Y, Wang YL, Zhou GY, Kai GY. Optimization of induction and culture conditions and tropane alkaloid production in hairy roots of Anisodus tanguticus. Biotechnol Bioproc E 2008; 13(5): 606-612.

3. Zhang $X F$, Wang $H$. The variation of the contents of four tropane alkaloids in Anisodus tanguticus. Acta Bot Boreal-Occident Sin 2002; 22(3): 630-634.

4. Wang $H$, Zhang XF, Chen GC, Li TC, Zhou GY, Shen JW. Comparative study of contents of four tropane alkaloids in cultural and wild Anisodus tanguticus. Boreal-Occident Sin 2005; 25(3): 575-577.

5. Chinese Academy of Sciences, China Flora Editorial Board. China flora. Science Press: Beijing; 2004; $p 26$.

6. Li WF, Jiang JG, Chen J. Chinese medicine and its modernization demands. Arch Med Res 2008; 39(2): 246-251.

7. Chinese Pharmacopoeia Commission. Chinese pharmacopoeia (Volume I). China Medical Science Press: Beijing; 2015.

8. Kong $W J$, Zhao YL, Shan $L M$, Xiao XH, Guo WY. Investigation on the spectrum-effect relationships of EtOAc extract from Radix Isatidis based on HPLC fingerprints and microcalorimetry. J Chromatogr $B$ Analyt Technol Biomed Life Sci 2008; 871(1): 109-114.

9. Kong WJ, Zhao YL, Xiao XH, Wang JB, Li HB, Li ZL, Jin $C$, Liu Y. Spectrum-effect relationships between ultraperformance liquid chromatography fingerprints and anti-bacterial activities of Rhizoma coptidis. Anal Chim Acta 2009; 634(2): 279-285.

10. The National Research Council of the National Academy of Science. Guide for the Care and Use of Laboratory Animals: Eight Edition. The National Academies Press: Washington, D.C.; 2010.
11. Jiang $Y$, Zhong $M$, Gou $Y$, Peng $W$, Zhou J, Wu $P$, Ma $Y$. Development of a more specific and accurate multiple reaction monitoring method based on GC-EI/MS/MS for simultaneously monitoring and determining 34 kinds of pesticides in Qianjinzhidai pills. J Chromatogr B Analyt Technol Biomed Life Sci 2015; 983-984: 47-54.

12. Jiang YB, Lu XL, Peng W, Deng W, Ma YY. Study on the influence of sulfur fumigation on chemical constituents of Angelicae dahuricae Radix (Baizhi). Trop J Pharm Res 2015; 14(5): 815-821.

13. Department of Phytochemistry, Institute of Materia Medica, Chinese Academy of Medical Sciences, Institute of Medical Science in Qinghai. Chemical studies of anisodamine. Acta Chim Sinica 1976; 34(1): 39-44.

14. Xie JX, Zhou J, Zhang CZ, Yang JH, Chen XX. Improvement of studies on total synthesis of anisodine. Acta Acad Med Sinica 1982; 4(2): 92-96.

15. Xu JY, Zhu PC, Zhou GY, Chen GC. Contents of three tropane alkaloids in cultivated Anisodus tanguticus by HPLC. Nat Prod Res Dev 2010; 22: 90-92.

16. Kuang HX. Chinese Medicine Chemistry. China Press of Traditional Chinese Medicine: Beijing; 2003; $p 328$.

17. $Y u Z Y$, Wang $X L$. Progress in extraction and purification of alkaloids. Chem Ind Eng Prog 2006; 25(3): 259-263.

18. Gupta AK, Parasar D, Sagar A, Choudhary V, Chopra BS, Garq R, Ashish, Khatri N. Analgesic and antiinflammatory properties of gelsolin in acetic acid induced writhing, tail immersion and carrageenan induced paw edema in mice. PloS One 2015; 10(8): e0135558.

19. Shang $X$, Wang $D$, Miao $X$, Wang $Y$, Zhang J, Wang $X$, Zhang $Y$, Pan $H$. Antinociceptive and anti-tussive activities of the ethanol extract of the flowers of Meconopsis punicea Maxim. BMC Complement Altern Med 2015; 15(1): 154.

20. Sun $L Q$, Ding XP, Qi J, Yu H, He SA, Zhang J, Ge HX. Antioxidant anthocyanins screening through spectrumeffect relationships and DPPH-HPLC-DAD analysis on nine cultivars of introduced rabbiteye blueberry in China. Food Chem 2012; 132(2): 759-765.

21. Xiao S, Fei CZ, Zhang LF, Zheng WL, Zhang KY, Xue $F Q$. Spectrum-effect relationship between high performance liquid chromatography fingerprints and anticoccidial activities of a compound Chinese medicine. J Integr Agr 2014; 13(5): 1082-1089.

22. Zeng JH, Ren $L Y, X u Y$, Dai $P$, Chen $X$, Wang J, Wang $\mathrm{XH}$, Wang JH. Study on spectrum-effect relationship between fingerprint of essential oil and of anti-tumor effect from Curcuma kwangsiensis. Afr $J$ Pharm Pharmaco 2012; 6(18): 1348-1351.

23. Zhu CS, Zhang B, Lin ZJ, Wang XJ, Zhou $Y$, Sun $X X$, Xiao ML. Relationship between high-performance liquid chromatography fingerprints and uric acid-lowering activities of Cichorium intybus L. Molecules 2015; 20(5): 9455-9467. 